\title{
Less invasive surfactant administration versus intubation for surfactant delivery in preterm infants with respiratory distress syndrome: a systematic review and meta-analysis
}

\author{
Jose C Aldana-Aguirre, ${ }^{1}$ Merlin Pinto, ${ }^{1}$ Robin M Featherstone, ${ }^{2}$ Manoj Kumar ${ }^{1,3}$
}

\begin{abstract}
- Additional material is published online only. To view please visit the journal online (http://dx.doi.org/10.1136/ archdischild-2015-310299).

${ }^{1}$ Neonatal Division, Department of Pediatrics, University of Alberta, Edmonton, Canada ${ }^{2}$ Department of Pediatrics, Alberta Research Centre for Health Evidence, University of Alberta, Edmonton, Canada ${ }^{3}$ Alberta Health Services, Edmonton, Canada
\end{abstract}

\section{Correspondence to} Dr Manoj Kumar, Department of Pediatrics, Edmonton Clinical Health Academy, Room 3-528, 1140587 Avenue NW, Edmonton, Alberta, Canada T6G 1C9; manojk@ualberta.ca

Received 6 December 2015 Revised 8 July 2016 Accepted 12 July 2016 Published Online First 16 November 2016

\section{CrossMark}

To cite: Aldana-Aguirre JC, Pinto M, Featherstone RM, et al. Arch Dis Child Fetal Neonatal Ed 2017;102:F17F23.

\begin{abstract}
Context In spontaneously breathing preterm infants with respiratory distress syndrome (RDS) receiving nasal continuous positive airway pressure, a method of less invasive surfactant administration (LISA) using a thin catheter has been described as an alternative to endotracheal intubation for surfactant delivery to reduce lung injury.
\end{abstract}

Objective A systematic review of randomised controlled trials (RCTs) comparing LISA with the standard method of surfactant delivery for clinical outcomes. Methods Medline, CENTRAL and Embase databases were searched (until 29 October 2015). Additional citations were identified from trial registries, conference proceedings and the bibliographies of selected articles. The included studies were RCTs enrolling preterm infants with RDS and compared LISA technique with intubation for surfactant delivery for any of the prespecified clinical outcomes.

Results Six RCTs were identified, enrolling a total of 895 infants. The use of LISA technique reduced the composite outcome of death or bronchopulmonary dysplasia (BPD) at 36 weeks (risk ratio (RR) $=0.75$ (95\% $\mathrm{Cl} 0.59$ to 0.94$), p=0.01), \mathrm{BPD}_{36}$ among survivors ( $R R=0.72$ (0.53 to 0.97$), p=0.03)$, need for mechanical ventilation within 72 hours of birth ( $R R=0.71$ ( 0.53 to $0.96), p=0.02$ ) or need for mechanical ventilation anytime during the neonatal intensive care unit stay $(R R=0.66(0.47$ to 0.93$), p=0.02)$. There were no differences noted for the outcome of death and other neonatal morbidities. Procedure failure rate on the first attempt and the need for additional doses of surfactant were not different between the intervention groups. Conclusions LISA technique for surfactant delivery results in a lesser need for mechanical ventilation in infants with RDS, reduction in the composite outcome of death or $\mathrm{BPD}$ at 36 weeks, and $\mathrm{BPD}_{36}$ among survivors.

\section{BACKGROUND}

Respiratory distress syndrome (RDS) is a common neonatal condition in premature infants. Its treatment often requires the use of surfactants, which have been shown to reduce the risk of death and bronchopulmonary dysplasia (BPD) in this population. ${ }^{12}$ The most common technique for surfactant delivery currently involves endotracheal intubation and short-duration mechanical ventilation. However, the lungs of premature infants are particularly susceptible to ventilator-induced lung injury. ${ }^{3-7}$ The use of non-invasive ventilation with nasal continuous positive airway pressure (CPAP) has been

\section{What is already known on the topic?}

- Pulmonary surfactants reduce the risk of death and bronchopulmonary dysplasia (BPD) in preterm infants with respiratory distress syndrome.

- Lungs of preterm infants are susceptible to injury from mechanical ventilation.

- In preterm infants stabilized on nasal CPAP, less invasive surfactant administration techniques that avoid mechanical ventilation may further reduce the risk of death or BPD.

\section{What this study adds?}

Less invasive surfactant administration reduces the composite outcome of death or bronchopulmonary dysplasia, need for mechanical ventilation, and BPD36 among survivors.

shown to cause less alveolar injury compared with mechanical ventilation via endotracheal tube. ${ }^{8-10}$

Currently, the preferred strategy for management of RDS is nasal CPAP at onset with selective use of surfactant for those infants with increasing oxygen requirements. ${ }^{11-14}$ Infants meeting the criteria for surfactant use are intubated and briefly ventilated for surfactant delivery by a protocol often referred to as InSurE (Intubation, Surfactant administration and Extubation)..$^{15-18}$

To prevent intubation for surfactant delivery in preterm infants with RDS, less invasive surfactant administration (LISA) techniques have been described. ${ }^{19-22}$ Of these techniques, the use of a thin catheter for intratracheal surfactant delivery in spontaneously breathing preterm infants on nasal CPAP is the most studied, ${ }^{23}$ with proposed benefits in terms of better survival and decreased need for mechanical ventilation. ${ }^{24}$

Our objective was to conduct a systematic review of randomised controlled trials (RCTs) comparing LISA technique using a thin catheter with endotracheal intubation for surfactant delivery for pertinent neonatal outcomes.

\section{METHODS}

Search strategy

The research librarian in collaboration with the research team conducted structured searches on 
subject headings and keywords for concepts related to surfactant application in preterm infants (see online supplementary appendix 1). The initial search was conducted in the first week of September 2014 employing the following electronic databases: Ovid Medline (1946 to date), Cochrane Central Register of Controlled Trials (CENTRAL) via Cochrane Library (from inception to date) and Ovid Embase (1980 to date). The search was updated on 29 October 2015. Additional citations were identified from trial registries (clinicaltrials.gov, http://www.who.int/ ictrp/en/), conference proceedings (2011-2015 abstracts of annual meetings of Pediatric Academic Societies and European Society for Pediatric Research) and the bibliographies of selected articles.

\section{Study selection and data extraction}

Two reviewers independently searched for eligible studies and the discrepancies were resolved through discussion with a third reviewer. Studies were included if they met the following criteria: randomised sequence generation, compared LISA technique with the standard technique of surfactant delivery involving endotracheal intubation and measured one or more of the following outcomes: death and/or BPD at 36-week gestation, need for mechanical ventilation or any other neonatal morbidities. Data were extracted by one reviewer using a standardised form and checked independently for accuracy by two other reviewers. Primary authors of the included studies were contacted for clarifications and additional information, if needed. Our primary outcome was a composite of death prior to 36-week gestation or $\mathrm{BPD}_{36}$.

\section{Assessment of bias}

We addressed methodological quality as per the Cochrane risk of bias tool, ${ }^{25}$ which includes items for adequacy of random sequence generation, allocation concealment, blinding of the caregivers and the assessors, incomplete outcome data reporting or selective reporting. Discrepancies were resolved through discussion and consensus among the review team.

\section{Data analysis}

Studies were pooled using random effects model. ${ }^{26}$ Risk ratio (RR) with its 95\% CI was chosen as the principal summary measure for assessing treatment effect. Data were analysed using RevMan V.5.3. An a priori sensitivity analysis was planned for studies that explicitly stated InSurE technique as the method of surfactant delivery for control group. The study is reported according to the PRISMA guidelines (http://www.prismastatement.org) (see online supplementary appendix 2). $\mathrm{I}^{2}$ statistic was calculated for each analysis to quantify heterogeneity across studies. If substantial $\left(\mathrm{I}^{2}>50 \%\right)$ heterogeneity was detected, the potential causes for its existence were explored and further sensitivity analyses were undertaken.

\section{RESULTS}

Figure 1 shows the flow of the studies through the selection process. We identified six RCTs, enrolling a total of 895 preterm infants. ${ }^{27-32}$ Brief descriptions and main characteristics of the included trials are presented in table 1. Curosurf was the predominant surfactant used in the included studies. The use of antenatal steroids was similar in the LISA and the control groups for each study. The data on caffeine (or other methylxanthines) use were available from five trials. Three trials prescribed these agents to nearly all participants, ${ }^{27} 2832$ and the other two trials restricted the use of methylxanthines according to gestation (all participants $<32$ weeks' gestational age) ${ }^{29}$ or

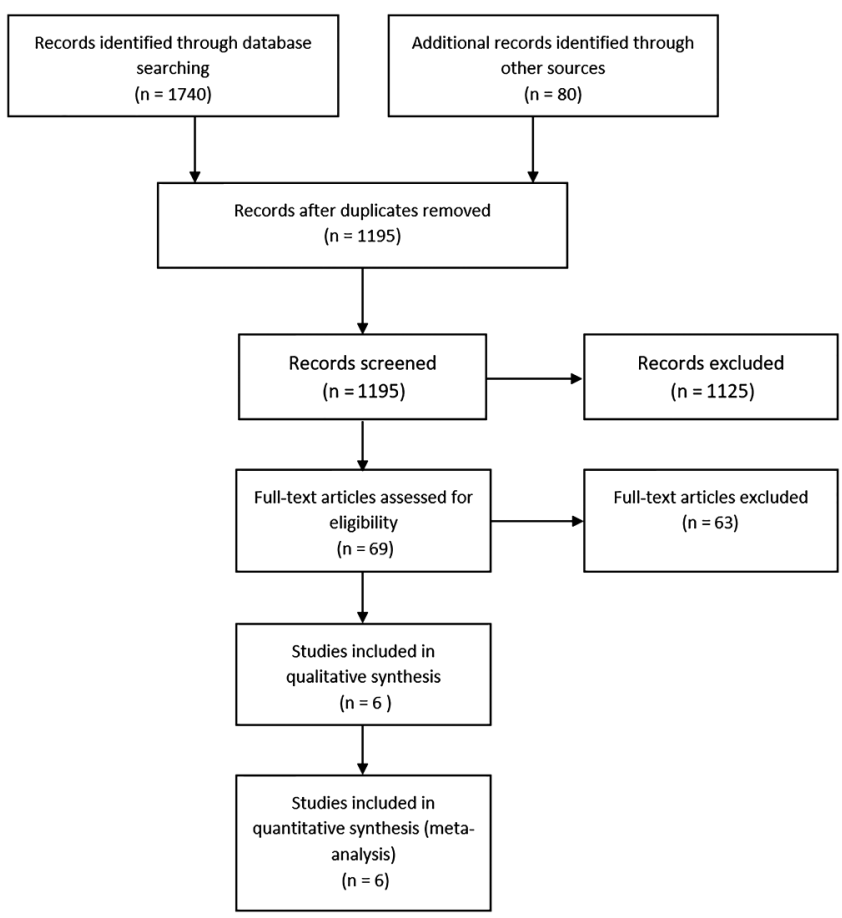

Figure 1 A PRISMA flow chart for the selection of eligible studies. BLES, bovine lipid extract surfactant; LMA, laryngeal mask airway; nCPAP: nasal CPAP; PRISMA, Preferred Reporting Items for Systematic Reviews and Meta-Analyses.

birth weight (all participants $<1250 \mathrm{~g}$ ). ${ }^{31}$ The starting time for these agents was not provided for comparison, although Kribs et $a l^{32}$ stated that the LISA group participants received caffeine earlier than controls who received caffeine at extubation. The use of postnatal steroids was reported in only two trials ${ }^{27} 32$ and was comparable in the intervention groups.

In all studies, the enrolled subjects were initiated on nasal CPAP (at 4-8 cm of $\mathrm{H}_{2} \mathrm{O}$ pressure) for management of RDS prior to randomisation. The criteria for providing surfactant were comparable between the intervention groups (ie, similar threshold of fractional inspired oxygen $\left(\mathrm{FiO}_{2}\right)$ and/or severity of respiratory distress in both groups) in all but one trial. ${ }^{27}$ Göpel et $a l^{27}$ used $\mathrm{FiO}_{2}$ of $>30 \%$ as a criterion for surfactant delivery in the LISA group, whereas in the control group the $\mathrm{Fio}_{2}$ threshold for surfactant use was allowed as per site-specific guidelines. However, this did not lead to a significant difference between the two groups in terms of the $\mathrm{FiO}_{2}$ requirements at the time of surfactant delivery (median (IQR) $\mathrm{FiO}_{2}: 40 \%(35 \%-55 \%)$ in the LISA group vs $45 \%(40 \%-$ $60 \%)$ in the control group), as well as the proportion of subjects requiring surfactant $(74 \%$ vs $65 \%, \mathrm{p}=0.19)$.

\section{Risk of bias assessment}

Table 2 shows the risk of bias assessment of the included studies. Three studies 282931 did not adequately describe the method of randomisation and two studies ${ }^{29} 30$ did not describe the method of allocation concealment. As expected, no blinding of interventions in any of the studies was attempted (technically difficult to perform given the type of interventions). This could have resulted in bias for some important outcomes such as 'need for mechanical intubation'. However, all studies satisfactorily described their objective criteria for rescue intubation to minimise this bias. Göpel et $a l^{27}$ used somewhat different criteria for the surfactant delivery in the two intervention groups (as explained above). 
Table 1 Baseline characteristics of the included studies

\begin{tabular}{|c|c|c|c|c|c|}
\hline Study & $\begin{array}{l}\text { Population, settings } \\
\text { Surfactant }\end{array}$ & Criteria for surfactant & LISA group & Intubation group & Comments \\
\hline Göpel et $a l^{27}$ & $\begin{array}{l}\text { GA: } 26-28 \text { weeks } \\
\text { Germany, multi-centre } \\
\text { (12 NICUs) } \\
\text { Curosurf/bovine } 100 \mathrm{mg} / \mathrm{kg}\end{array}$ & $\begin{array}{l}\text { Subjects on nCPAP; and } \\
\mathrm{FiO}_{2} \geq 0.3 \text { for LISA group } \\
\text { and variable Fio } \\
\text { threshold (between } 0.3 \\
\text { and } 0.6 \text { ) for intubation } \\
\text { group }\end{array}$ & $\begin{array}{l}\mathrm{N}=108 \\
\mathrm{GA}: 27.6(0.8) \text { weeks } \\
\text { Birth weight*: } 975(244) \mathrm{g} \\
2.5-5 \mathrm{Fr} \text { catheter } \\
\text { Magill forceps } \\
\text { AS: } 96 \%\end{array}$ & $\begin{array}{l}\mathrm{N}=112 \\
\text { GA: } 27.5(0.8) \text { weeks } \\
\text { Birth Wt: } 938(205) \mathrm{g} \\
\text { InSurE protocol: unclear } \\
\text { AS: } 96 \%\end{array}$ & $\begin{array}{l}\text { Use of premedication } \\
\text { was at the discretion of } \\
\text { the attending physicians. } \\
\text { Not all patients received } \\
\text { surfactant in either } \\
\text { group. }\end{array}$ \\
\hline Kanmaz et al ${ }^{28}$ & $\begin{array}{l}\text { GA: }<32 \text { weeks } \\
\text { Turkey, single centre } \\
\text { Curosurf } 100 \mathrm{mg} / \mathrm{kg}\end{array}$ & $\begin{array}{l}\text { Subjects on nCPAP with } \\
\mathrm{FiO}_{2} \geq 0.4\end{array}$ & $\begin{array}{l}\mathrm{N}=100 \\
\mathrm{GA}: 28 \text { (2) weeks } \\
\text { Birth weight: } 1093(270) \mathrm{g} \\
5 \mathrm{Fr} \text { feeding tube } \\
\text { AS: } 73 \%\end{array}$ & $\begin{array}{l}\mathrm{N}=100 \\
\mathrm{GA} 28.3 \text { (2) weeks } \\
\text { Birth weight: } 1121(270) \mathrm{g} \\
\text { InSurE protocol: yes } \\
\text { AS: } 81 \%\end{array}$ & $\begin{array}{l}\text { No premedication was } \\
\text { used during both } \\
\text { procedures. }\end{array}$ \\
\hline Mirnia et $a l^{29}$ & $\begin{array}{l}\text { GA: } 27-32 \text { weeks } \\
\text { Iran, multi-centre } \\
\text { (3 NICUs) } \\
\text { Curosurf } 200 \mathrm{mg} / \mathrm{kg}\end{array}$ & $\begin{array}{l}\text { Subjects on nCPAP with } \\
\mathrm{FiO}_{2} \geq 0.3\end{array}$ & $\begin{array}{l}\mathrm{N}=66 \\
\mathrm{GA}: 29.6(1.7) \text { weeks } \\
\text { Birth weight: } 1339(406) \mathrm{g} \\
5 \mathrm{Fr} \text { feeding tube } \\
\text { AS: } 66.7 \%\end{array}$ & $\begin{array}{l}\mathrm{N}=70 \\
\mathrm{GA}: 29.6 \text { (1.7) weeks } \\
\text { Birth weight: } 1304 \text { (331) g } \\
\text { InSurE protocol: yes } \\
\text { AS: } 62.9 \%\end{array}$ & $\begin{array}{l}\text { Atropine for } \\
\text { premedication }\end{array}$ \\
\hline Bao et $a \beta^{30}$ & $\begin{array}{l}\text { GA: } 28-32 \text { weeks } \\
\text { China, single centre } \\
\text { Curosurf } 200 \mathrm{mg} / \mathrm{kg}\end{array}$ & $\begin{array}{l}\text { Subjects on nCPAP with } \\
\mathrm{FiO}_{2} \geq 0.3 \text { ( } 28-29 \\
\text { weeks) or } \geq 0.35 \text { ( } 30-32 \\
\text { weeks) }\end{array}$ & $\begin{array}{l}\mathrm{N}=47 \\
\mathrm{GA}: 29.1 \text { (1.5) weeks } \\
\text { Birth weight: } 1034(221) \mathrm{g} \\
\text { 16-guage catheter }(\sim 5 \mathrm{Fr}) \\
\text { AS: } 89.4 \%\end{array}$ & $\begin{array}{l}\mathrm{N}=43 \\
\mathrm{GA}: 29.3 \text { (1.6) weeks } \\
\text { Birth weight: } 1087 \text { (198) g } \\
\text { InSurE protocol: yes } \\
\text { AS: } 93 \%\end{array}$ & \\
\hline $\begin{array}{l}\text { Mohammadizadeh } \\
\text { et al }{ }^{31}\end{array}$ & $\begin{array}{l}\text { GA: }<34 \text { weeks } \\
\text { Iran, multi-centre } \\
\text { (2 NICUs) } \\
\text { Curosurf } 200 \mathrm{mg} / \mathrm{kg}\end{array}$ & $\begin{array}{l}\text { Subjects on nCPAP with } \\
\mathrm{FiO}_{2} \geq 0.3 \text { or } \\
\text { moderate-to-severe RDS } \\
\text { (Silverman score } \geq 5 \text { ) }\end{array}$ & $\begin{array}{l}\mathrm{N}=19 \\
\mathrm{GA}: 30 \text { (2) weeks } \\
\text { Birth weight: } 1289(219) \mathrm{g} \\
4 \text { Fr feeding tube } \\
\text { Magill forceps } \\
\text { AS: } 84.2 \%\end{array}$ & $\begin{array}{l}\mathrm{N}=19 \\
\mathrm{GA} 31 \text { (2) weeks } \\
\text { Birth weight: } 1428 \text { (272) g } \\
\text { InSurE protocol: yes } \\
\text { AS: } 89.5 \%\end{array}$ & $\begin{array}{l}\text { Atropine for } \\
\text { premedication }\end{array}$ \\
\hline Kribs et $a l^{32}$ & $\begin{array}{l}\text { GA: } 23 \text { to }<27 \text { weeks } \\
\text { Germany, multi-centre } \\
\text { (13 NICUs) } \\
\text { Curosurf } 100 \mathrm{mg} / \mathrm{kg}\end{array}$ & $\begin{array}{l}\text { Subjects on nCPAP with } \\
\mathrm{FiO}_{2} \geq 0.3 \text { or } \\
\text { moderate-to-severe RDS } \\
\text { (Silverman score } \geq 5 \text { ) }\end{array}$ & $\begin{array}{l}\mathrm{N}=107 \\
\text { GA: } 25.3 \text { (1.1) weeks } \\
\text { Birth weight: } 711 \text { (195) g } \\
\text { 4 Fr catheter } \\
\text { Magill forceps } \\
\text { AS: } 98.1 \%\end{array}$ & $\begin{array}{l}\mathrm{N}=104 \\
\mathrm{GA}: 25.2(0.91) \text { weeks } \\
\text { Birth weight: } 674(165) \mathrm{g} \\
\text { InSurE protocol: } \mathrm{no} \\
\text { (centres were advised to } \\
\text { extubate as soon as possible) } \\
\text { AS: } 98.1 \%\end{array}$ & $\begin{array}{l}\text { Use of premedication } \\
\text { was not specified. }\end{array}$ \\
\hline
\end{tabular}

*Data are mean (SD) for all studies.

$\mathrm{AS}$, antenatal steroids; Fio ${ }_{2}$, fractional inspired oxygen; GA, gestational age; InSurE, Intubation, Surfactant and Extubation; LISA, less invasive surfactant administration; NICU, neonatal intensive care unit; RDS, respiratory distress syndrome.

\section{Outcomes}

Death or BPD at 36 weeks

All studies provided data for our primary outcome. A metaanalysis showed that the LISA technique resulted in a significant reduction in the composite outcome of death or BPD at 36 weeks ( $R R=0.75$ (95\% CI 0.59 to 0.94$), p=0.01$ ) (figure 2). A sensitivity analysis restricted to studies clearly stating the use of the InSurE protocol for control groups showed similar results (four studies, ${ }^{28-31} \mathrm{RR}=0.66$ (95\% CI 0.46 to 0.94 ), $\mathrm{p}=0.02$ ). An analysis restricted to studies with the lowest risk for bias revealed similar results (two studies, ${ }^{28} 32 \mathrm{RR}=0.75$ (95\% CI 0.57 to 1.00$), p=0.05)$. There was no significant heterogeneity noted in any of these analyses.

Death

The meta-analysis showed no difference for the outcome of death $(\mathrm{RR}=0.85$ (95\% CI 0.48 to 1.52$), \mathrm{p}=0.58$ ) (figure 3$)$. The sensitivity analysis restricted to trials ${ }^{28-31}$ explicitly stating the use of InSurE protocol in control arms revealed similar results.

\section{$\mathrm{BPD}_{36}$ among survivors}

The meta-analysis showed that the LISA technique resulted in a significant reduction in this outcome $(\mathrm{RR}=0.72$ (95\% CI 0.53 to $0.97), p=0.03$ ) (figure 4 ). The sensitivity analysis restricted to trials stating the use of InSurE protocol in the control arms ${ }^{28-31}$ revealed similar point estimate for treatment effect $(R R=0.70$
(95\% CI 0.42 to 1.16 ), $\mathrm{p}=0.16$ ). The analysis restricted to studies with the lowest risk for bias revealed similar results (two studies, ${ }^{28}{ }^{32} \mathrm{RR}=0.70$ (95\% CI 0.48 to 1.03 ), $\mathrm{p}=0.07$ ).

\section{Mechanical ventilation}

Four studies ${ }^{28-31}$ presented data for the outcome of need for mechanical ventilation within 72 hours of birth, and three studies $^{27} 2832$ for the outcome of need for mechanical ventilation anytime during hospitalisation. The meta-analysis showed that the LISA group infants had a lesser need for mechanical ventilation within 72 hours $(\mathrm{RR}=0.71$ (95\% CI 0.53 to 0.96 ), $\mathrm{p}=0.02$ ) (figure 5), and for mechanical ventilation anytime during the neonatal intensive care unit (NICU) stay $(\mathrm{RR}=0.66$ (95\% CI 0.47 to 0.93 ), $\mathrm{p}=0.02$ ) (figure 6). The latter analysis showed significant heterogeneity $\left(\mathrm{I}^{2}=85 \%\right)$ resulting from more favourable results seen in the trial by Göpel et al ${ }^{27}$ compared with those seen in the other trials. When data from this study were excluded the heterogeneity resolved $\left(\mathrm{I}^{2}=0 \%\right)$, and the pooled estimate remained significant $(\mathrm{RR}=0.76$ (95\% CI 0.65 to 0.85$), p<0.001)$. The beneficial effect with LISA remained when analyses were restricted to studies ${ }^{28} 32$ with the lowest risk for bias.

The included studies also presented data for the duration of mechanical ventilation in the intervention groups (table 3 ). However, those data were in variable units, preventing pooling of results for a meta-analysis. 


\section{Original article}

Table 2 Risk of bias assessments

\begin{tabular}{|c|c|c|c|c|c|c|c|}
\hline Study & $\begin{array}{l}\text { Random } \\
\text { sequence } \\
\text { generation }\end{array}$ & $\begin{array}{l}\text { Allocation } \\
\text { concealment }\end{array}$ & $\begin{array}{l}\text { Blinding of } \\
\text { participant and } \\
\text { personnel }\end{array}$ & $\begin{array}{l}\text { Blinding of } \\
\text { outcome } \\
\text { assessment }\end{array}$ & $\begin{array}{l}\text { Incomplete } \\
\text { outcome data }\end{array}$ & $\begin{array}{l}\text { Selective } \\
\text { reporting }\end{array}$ & Other biases \\
\hline Göpel et $a l^{27}$ & Low risk & Low risk & High risk & High risk & Low risk & Low risk & $\begin{array}{l}\text { Criteria for providing surfactant were } \\
\text { not similar across the two groups }\end{array}$ \\
\hline Kanmaz et al ${ }^{28}$ & Unclear & Low risk & High risk & High risk & Low risk & Low risk & \\
\hline Mirnia et $a l^{29}$ & Unclear & Unclear & High risk & High risk & Low risk & Unclear* & \\
\hline Bao et $a l^{30}$ & Low risk & Unclear & High risk & High risk & Low risk & Uncleart & Trial stopped early \\
\hline Mohammadizadeh et $a l^{31}$ & Unclear & Low risk & High risk & High risk & Low risk & High $\ddagger$ & \\
\hline Kribs et al ${ }^{32}$ & Low risk & Low risk & High risk & High risk & Low risk & Low risk & \\
\hline
\end{tabular}

${ }^{*}$ Trial protocol not registered in a public trial registry.

†Trial protocol registered after completion of the study.

¥Outcomes of common neonatal morbidities, that is, NEC, ROP and PDA requiring treatment not provided.

NEC, necrotising enterocolitis; PDA, patent ductus arteriosus; ROP, retinopathy of prematurity.

\begin{tabular}{|c|c|c|c|c|c|c|c|c|c|c|}
\hline Study or Subgroup & \multicolumn{2}{|c|}{ LISA } & \multicolumn{2}{|c|}{ Control } & Weight & \multicolumn{2}{|l|}{ Risk Ratio } & \multicolumn{2}{|c|}{$\begin{array}{c}\text { Risk Ratio } \\
\text { M-H, Random, } 95 \% \mathrm{Cl}\end{array}$} & \\
\hline Gopel 2011 & 15 & 108 & 17 & 112 & $13.3 \%$ & $0.92[0.48,1.74]$ & & $\rightarrow$ & & \\
\hline Kanmaz 2013 & 22 & 100 & 32 & 100 & $25.1 \%$ & $0.69[0.43,1.10]$ & & $\rightarrow$ & & \\
\hline Mirnia 2013 & $?$ & 66 & 16 & 70 & $8.1 \%$ & $0.46[0.20,1.06]$ & & & & \\
\hline Kribs 2015 & 35 & 107 & 43 & 104 & $43.3 \%$ & $0.79[0.55,1.13]$ & & $\Rightarrow$ & & \\
\hline Bao 2015 & $?$ & 47 & 6 & 43 & $5.4 \%$ & $1.07[0.39,2.93]$ & & & & \\
\hline Mohammadizadeh 2015 & 4 & 19 & 7 & 19 & $4.9 \%$ & $0.57[0.20,1.63]$ & & & - & \\
\hline Total $(95 \% \mathrm{Cl})$ & & 447 & & 448 & $100.0 \%$ & $0.75[0.59,0.94]$ & & 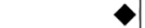 & & \\
\hline Total events & 90 & & 121 & & & & & & & \\
\hline $\begin{array}{l}\text { Heterogeneity: } \operatorname{Tau}^{2}=0 . \\
\text { Test for overall effect: } Z=\end{array}$ & $\begin{array}{l}\mathrm{Chi}^{2}=2 \\
46(P=0\end{array}$ & $\begin{array}{l}63, \mathrm{df}= \\
.01)\end{array}$ & $=5(P=0$. & $.76) ; 1^{2}$ & $0 \%$ & & 0.01 & $\begin{array}{c}0.1 \\
\text { Favours [LISA] }\end{array}$ & $\begin{array}{c}10 \\
\text { Favours [Control] }\end{array}$ & $100^{\circ}$ \\
\hline
\end{tabular}

Figure 2 Composite outcome of death or bronchopulmonary dysplasia at 36 weeks. LISA, less invasive surfactant administration.

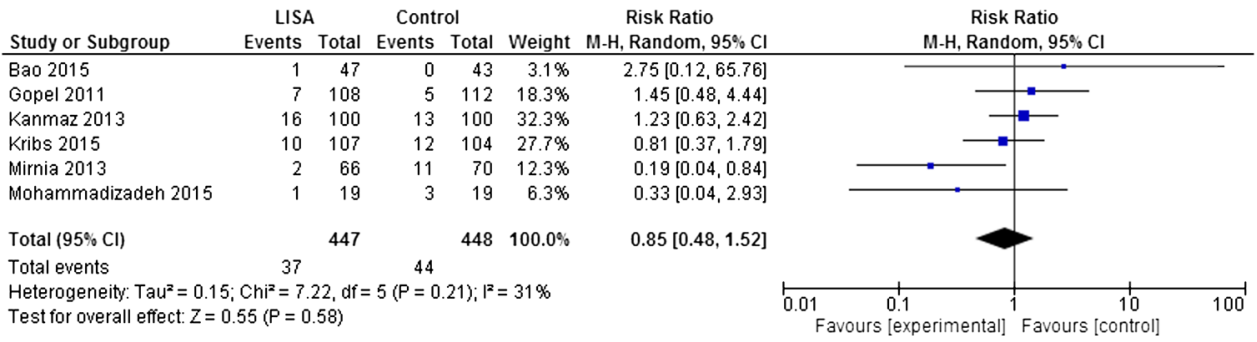

Figure 3 A meta-analysis of the outcome of death in study participants. LISA, less invasive surfactant administration.

\section{Other neonatal morbidities}

The meta-analysis showed lesser pneumothoraces in the LISA group infants (five studies, ${ }^{27-30}{ }^{32} \mathrm{RR}=0.61$ (95\% CI 0.37 to $\left.1.02), \mathrm{p}=0.06, \mathrm{I}^{2}=0 \%\right)$. Similarly, a non-significant reduction in the incidence of pulmonary haemorrhage was noted with LISA (three studies, ${ }^{27} 2832 \mathrm{RR}=0.63$ (95\% CI 0.29 to 1.37 ), $\mathrm{p}=0.24$ ). No significant differences were noted in outcomes of other neonatal morbidities, that is, patent ductus arteriosus requiring medical or surgical treatment, necrotising enterocolitis $\geq$ stage 2, retinopathy of prematurity $>$ stage 2 , intraventricular haemorrhage $>$ stage 2 and periventricular leukomalacia (table 4).

\section{Procedure-related outcomes}

There was a greater incidence of surfactant reflux noted with the LISA technique (three studies, ${ }^{28-30} \mathrm{RR}=2.52$ (95\% CI 1.47 to 4.31$), \mathrm{p}<0.001)$. However, this did not affect the number of subjects needing more than one dose of surfactant in the intervention groups (four studies, ${ }^{28-31} \mathrm{RR}=1.07$ (95\% CI 0.80 to 1.44), $\mathrm{p}=0.63)$. The outcome of failure of procedure on the first attempt was not different between the groups (four studies, ${ }^{28}{ }^{30-32} \mathrm{RR}=0.97$ (95\% CI 0.58 to 1.63$\left.), \mathrm{p}=0.91\right)$.

Two trials ${ }^{31} 32$ reported increased incidence of bradycardia and/or desaturations during the LISA procedure, while Bao et $a l^{30}$ reported a lesser incidence of these events in the LISA group. Kanmaz et $a l^{28}$ reported no such differences between the study groups.

\section{DISCUSSION}

The results of this systematic review of available RCTs show that in non-invasively ventilated preterm infants, the use of the LISA technique compared with that of endotracheal intubation for surfactant delivery was beneficial in terms of reduction in the composite outcome of death or BPD at 36 weeks, $\mathrm{BPD}_{36}$ among survivors and the need for mechanical ventilation. There was also a trend towards lower pneumothorax rates with LISA. These findings were robust to the sensitivity analyses performed. There were no differences noted in the outcome of death or in the rates of other neonatal morbidities. We included the study by Göpel et $a l^{27}$ where not all infants enrolled in the trial 


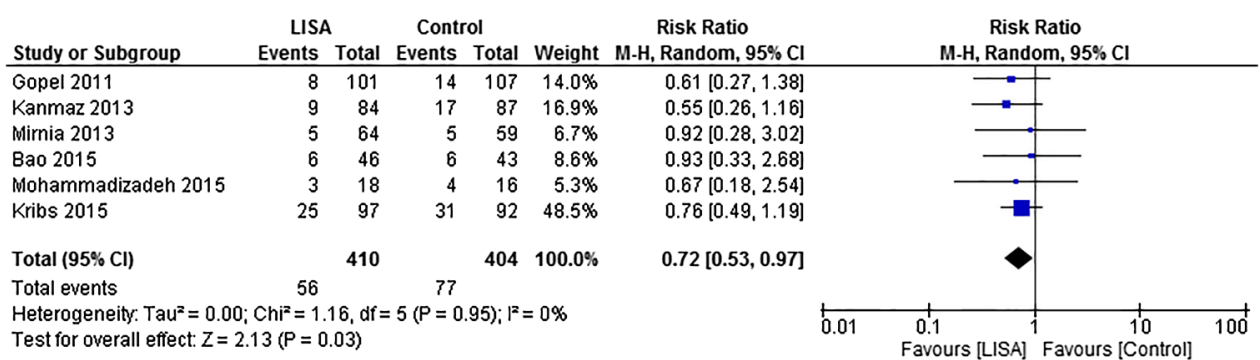

Figure 4 Bronchopulmonary dysplasia at 36 weeks among survivors. LISA, less invasive surfactant administration.

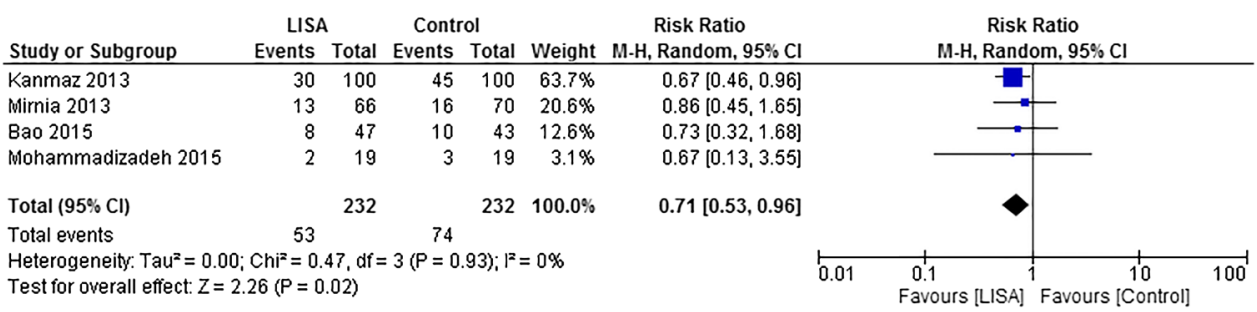

Figure 5 Need for mechanical ventilation within 72 hours from birth. LISA, less invasive surfactant administration.

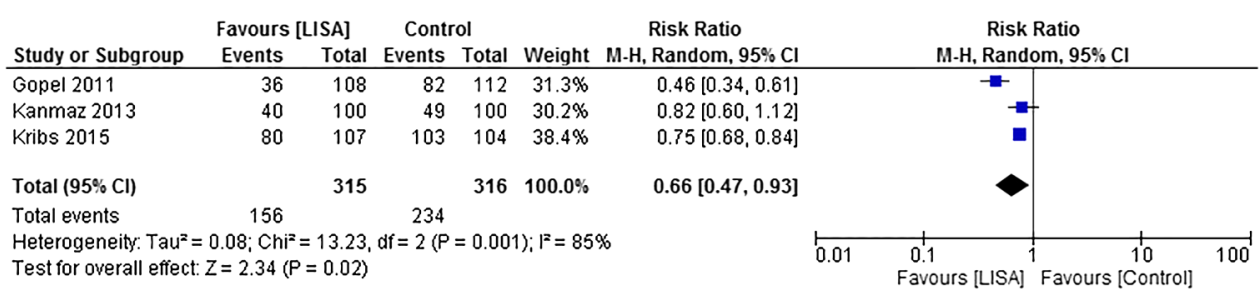

Figure 6 Need for mechanical ventilation anytime during the neonatal intensive care unit stay. LISA, less invasive surfactant administration.

Table 3 Duration of mechanical ventilation in the intervention groups for the included studies

\begin{tabular}{|c|c|c|c|c|}
\hline Study & Unit of measurement & LISA group & Control group & $p$ Value \\
\hline Göpel et $\left.a\right|^{27}$ & Days, median (IQR) & $0(0-3)$ & $2(0-5)$ & $<0.0001$ \\
\hline Kanmaz et al ${ }^{28}$ & Hours, median (range) & $35.6(0-756)$ & $64.1(0-489)$ & 0.006 \\
\hline Mirnia et $a l^{29}$ & Hours, mean (SEM) & $25.18 \pm 8.7$ & $13.44 \pm 3.7$ & 0.2 \\
\hline Bao et $a \beta^{30}$ & Days, mean (SD) & $6.7(3.5)$ & $7.4(4.3)$ & 0.4 \\
\hline Mohammadizadeh et $a l^{31}$ & Hours, mean (SD) & $36 \pm 16.9$ & $144 \pm 109.9$ & 0.2 \\
\hline Kribs et $a l^{32}$ & Days, median (IQR) & $5(0-17)$ & $7(2.5-19.5)$ & 0.03 \\
\hline
\end{tabular}

received surfactant (only those who met the criteria received surfactant), as the proportion of infants who received surfactant and the $\mathrm{FiO}_{2}$ requirement at the time of surfactant delivery were not statistically different between the two study arms. In the sensitivity analysis, the exclusion of data from this trial did not affect the main findings of this review.

We restricted our analysis to the LISA technique that involved surfactant delivery using a thin catheter. Other methods of surfactant delivery without intubation such as administration by nebulisation or with the use of LMA have been described in literature. ${ }^{21}{ }^{33-35}$ We did not evaluate those techniques as the literature on them is currently limited.

The pulmonary benefits seen with the LISA technique may be related to many factors. First, a few large mechanical breaths, which are often required with the current method of surfactant delivery following intubation, could cause lung injury in the early newborn period as described in animal studies. ${ }^{5}$ Second, the LISA technique allows for continuation of uninterrupted nasal CPAP support during the entire process of providing surfactant, preventing lung injury that could result from the temporary loss of functional lung capacity and atelectasis during the process of intubation. ${ }^{36}$ Lastly, the LISA technique largely depends on the spontaneous breathing effort of the newborns to distribute surfactant in the lungs, compared with the repeated positive pressure inflations with the InSurE technique, resulting in more rapid and complete tissue incorporation of the surfactant in the neonatal lung. ${ }^{37} 38$

The results of this systematic review suggest that the LISA technique should be the preferred method for delivering surfactant to spontaneously breathing preterm infants in the neonatal 
Table 4 Results of all outcomes studied

\begin{tabular}{|c|c|c|c|c|c|}
\hline Outcome & Studies & Participants & $\begin{array}{l}\text { LISA } \\
\text { events/N }\end{array}$ & $\begin{array}{l}\text { Controls } \\
\text { events/N }\end{array}$ & $\begin{array}{l}\text { Effect estimate } \\
\text { RR }(95 \% \mathrm{CI})\end{array}$ \\
\hline Death or BPD at 36 weeks & 6 & 895 & $90 / 447$ & $121 / 448$ & $0.75(0.59 \text { to } 0.94)^{*}$ \\
\hline BPD at 36 weeks in survivors & 6 & 814 & $56 / 410$ & $77 / 404$ & $0.72(0.53 \text { to } 0.97)^{*}$ \\
\hline Mortality & 6 & 895 & $37 / 447$ & $44 / 448$ & $0.85(0.48$ to 1.52$)$ \\
\hline Mechanical ventilation within 72 hours & 4 & 464 & $53 / 232$ & $74 / 232$ & $0.71(0.53 \text { to } 0.96)^{*}$ \\
\hline Mechanical ventilation anytime & 3 & 631 & $156 / 315$ & $234 / 316$ & $0.66(0.47 \text { to } 0.93)^{*}$ \\
\hline Pneumothorax & 5 & 854 & $23 / 426$ & $38 / 428$ & $0.61(0.37 \text { to } 1.02)^{* *}$ \\
\hline PDA requiring treatment & 5 & 857 & $153 / 428$ & $146 / 429$ & $1.02(0.89$ to 1.17$)$ \\
\hline $\mathrm{IVH} \geq$ stage 2 & 4 & 721 & $30 / 362$ & $45 / 359$ & $0.69(0.40$ to 1.17$)$ \\
\hline NEC stage $\geq 2 \dagger$ & 4 & 767 & $28 / 381$ & $33 / 386$ & 0.91 (0.56 to 1.47$)$ \\
\hline ROP >stage $2 \ddagger$ & 5 & 857 & $13 / 428$ & $13 / 429$ & $1.13(0.31$ to 4.10$)$ \\
\hline Surfactant reflux & 3 & 426 & $42 / 213$ & $16 / 213$ & $2.52(1.47 \text { to } 4.31)^{*}$ \\
\hline PVL & 3 & 521 & $10 / 262$ & $14 / 259$ & $0.84(0.21$ to 3.35$)$ \\
\hline Need for $>1$ dose of surfactant§ & 4 & 464 & $64 / 232$ & $59 / 232$ & $1.07(0.80$ to 1.44$)$ \\
\hline Failure of procedure on the first attempt & 4 & 572 & $56 / 289$ & $54 / 283$ & $0.97(0.58$ to 1.63$)$ \\
\hline Pulmonary haemorrhage & 3 & 631 & $10 / 315$ & $16 / 316$ & $0.63(0.29$ to 1.37$)$ \\
\hline \multicolumn{6}{|c|}{ 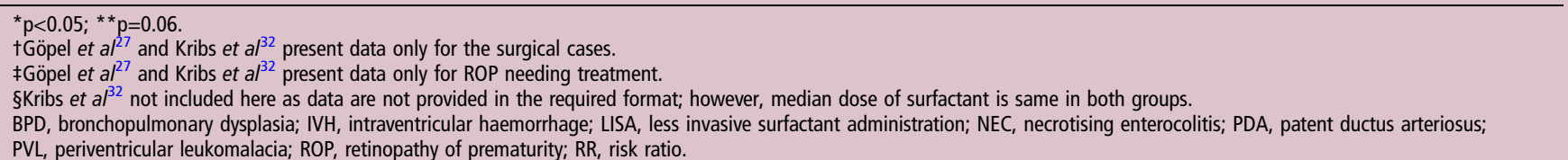 } \\
\hline
\end{tabular}

units. The findings of our systematic review differ from those of a meta-narrative review ${ }^{23}$ published previously, which concluded no significant difference in the outcome of BPD with the LISA technique. However, many new RCTs ${ }^{30-32}$ published since then were included in our meta-analyses, allowing us to provide more precise estimates for the neonatal outcomes studied. A recently published large cohort study, enrolling over 2200 preterm infants, ${ }^{39}$ confirms the findings of our systematic review.

The need for premedication with the LISA procedure was inconsistently reported in the included trials. It is difficult to comment from the available data whether the use of premedication would help reduce the incidence of bradycardia and/or desaturation episodes during the LISA procedure, as noted in some studies. ${ }^{3132}$ A recent cohort control study showed better comfort scores with the use of sedation but a greater risk of intubation during or within 24 hours after the procedure. ${ }^{40}$ Future studies could determine the benefits and the risks associated with the use of sedation during the LISA procedure.

The widespread implementation of LISA technique in the neonatal units would require formal training of healthcare personnel for this procedure. Several variations of the LISA technique have been described, such as the use of feeding tubes or semirigid vascular catheters, with or without the aid of Magill forceps. Further research would be needed to identify the most suitable technique for wider adoption.

\section{Limitations}

Our systematic review has a few limitations. None of the included trials provided data regarding long-term neurodevelopmental outcomes. However, a recent cohort study using historical controls showed no difference in long-term outcomes at school age with LISA. ${ }^{41}$ Two large multi-centre studies ${ }^{27} 32 \mathrm{did}$ not clearly mandate the use of the InSurE protocol in control groups. However, study investigators for both of these trials suggested extubation as soon as possible to the participating sites as expected with the InSurE protocol. The sensitivity analysis excluding data from those trials did not change the results of our primary outcome.

The included studies did not systematically report procedure-related side effects. However, the studies that presented these data did not reveal a greater failure rate with the LISA procedure on first attempt ${ }^{28} 30-32$ or the need for additional doses of surfactant. ${ }^{28-31}$

The majority of subjects enrolled in the included studies received a porcine surfactant (Curosurf). It is possible that the procedure-related side effects such as surfactant reflux, bradycardia and/or desaturation events may occur more frequently with bovine surfactants (BLES and Survanta) where the volume required is usually greater. A few ongoing RCTs (ECALMIST NCT01848262, MISTCPAP NCT01723683 and MIsurf NCT01615016) using bovine surfactants may answer this question with greater certainty in the coming years.

\section{CONCLUSIONS}

In spontaneously breathing preterm infants with RDS stabilised on nasal CPAP, the LISA technique for surfactant delivery resulted in less need for mechanical ventilation during the NICU stay and a reduction in the composite outcome of death or $\mathrm{BPD}$ at 36 weeks and $\mathrm{BPD}_{36}$ among survivors. There were no clinically significant side effects noted. For a widespread implementation of the LISA technique, training of healthcare personnel, standardisation of the procedure including the role of premedication and more experience with extremely preterm infants are recommended.

Contributors JCA-A contributed to all stages of the review, wrote the first draft of the manuscript and approved the final manuscript as submitted. MP contributed to the planning of the study, literature search, data extraction and risk of bias assessments, and approved the final manuscript as submitted. RMF contributed to the planning of the study and literature search, and approved the final manuscript as submitted. MK contributed to all stages of the review, reviewed all drafts of the manuscript and approved the final manuscript as submitted.

Competing interests None declared. 


\section{REFERENCES}

1 Seger N, Soll R. Animal derived surfactant extract for treatment of respiratory distress syndrome. Cochrane Database Syst Rev 2009;(2):CD007836.

2 Soll RF. Synthetic surfactant for respiratory distress syndrome in preterm infants. Cochrane Database Syst Rev 2000;(2):CD001149.

3 Hillman NH, Kallapur SG, Pillow JJ, et al. Airway injury from initiating ventilation in preterm sheep. Pediatr Res 2010;67:60-5

4 Brew N, Hooper SB, Allison BJ, et al. Injury and repair in the very immature lung following brief mechanical ventilation. Am J Physiol Lung Cell Mol Physiol 2011;301:L917-26.

5 Björklund LJ, Ingimarsson J, Curstedt T, et al. Manual ventilation with a few large breaths at birth compromises the therapeutic effect of subsequent surfactant replacement in immature lambs. Pediatr Res 1997;42:348-55.

6 Schmölzer GM, Te Pas AB, Davis PG, et al. Reducing lung injury during neonatal resuscitation of preterm infants. J Pediatr 2008;153:741-5.

7 Attar MA, Donn SM. Mechanisms of ventilator-induced lung injury in premature infants. Semin Neonatol 2002;7:353-60.

8 Aly $H$, Milner JD, Patel $K$, et al. Does the experience with the use of nasal continuous positive airway pressure improve over time in extremely low birth weight infants? Pediatrics 2004;114:697-702.

9 Polin RA, Sahni R. Newer experience with CPAP. Semin Neonatol 2002;7:379-89.

10 Jobe AH, Kramer BW, Moss TJ, et al. Decreased indicators of lung injury with continuous positive expiratory pressure in preterm lambs. Pediatr Res 2002;52:387-92

11 Sweet DG, Carnielli V, Greisen G, et al. European Association of Perinatal Medicine. European consensus guidelines on the management of neonatal respiratory distress syndrome in preterm infants--2013 update. Neonatology 2013;103:353-68.

12 Finer NN, Carlo WA, Walsh MC, et al. Early CPAP versus surfactant in extremely preterm infants. N Engl J Med 2010;362:1970-9.

13 Schmölzer GM, Kumar M, Pichler $G$, et al. Non-invasive versus invasive respiratory support in preterm infants at birth: systematic review and meta-analysis. BMJ 2013;347:f5980. . Review. Erratum in: BMJ. 2014;348:g58.

14 Fischer HS, Bührer C. Avoiding endotracheal ventilation to prevent bronchopulmonary dysplasia: a meta-analysis. Pediatrics 2013;132:e1351-60.

15 Verder H, Robertson B, Greisen G, et al. Surfactant therapy and nasal continuous positive airway pressure for newborns with respiratory distress syndrome. Danish-Swedish Multicenter Study Group. N Engl J Med 1994;331:1051-5.

16 Dunn MS, Kaempf J, de Klerk A, et al. Vermont Oxford Network DRM Study Group. Randomized trial comparing 3 approaches to the initial respiratory management of preterm neonates. Pediatrics 2011;128:e1069-76.

17 Bohlin K. RDS--CPAP or surfactant or both. Acta Paediatr Supp/ 2012;101:24-8

18 Bohlin K, Gudmundsdottir T, Katz-Salamon M, et al. Implementation of surfactant treatment during continuous positive airway pressure. J Perinatol 2007;27:422-7.

19 Aguar M, Vento M, Dargaville PA. Minimally invasive surfactant therapy: an update. Neoreviews 2014;15:e275-85. .

20 Pillow JJ, Minocchieri S. Innovation in surfactant therapy II: surfactant administration by aerosolization. Neonatology 2012;101:337-44.

21 Attridge JT, Stewart C, Stukenborg GJ, et al. Administration of rescue surfactant by laryngeal mask airway: lessons from a pilot trial. Am J Perinatol 2013;30:201-6.

22 Dargaville PA, Aiyappan A, Cornelius A, et al. Preliminary evaluation of a new technique of minimally invasive surfactant therapy. Arch Dis Child Fetal Neonatal Ed 2011;96:F243-8.
23 More K, Sakhuja P, Shah PS. Minimally invasive surfactant administration in preterm infants: a meta-narrative review. JAMA Pediatr 2014;168:901-8.

24 Klebermass-Schrehof K, Wald M, Schwindt J, et al. Less invasive surfactant administration in extremely preterm infants: impact on mortality and morbidity. Neonatology 2013;103:252-8.

25 Higgins JPT, Green S, eds. Cochrane Handbook for Systematic Reviews of Interventions Version 5.1.0 [updated March 2011]. The Cochrane Collaboration, 2011. http://www.cochrane-handbook.org (accessed Nov 2015)

26 DerSimonian R, Laird N. Meta-analysis in clinical trials. Control Clin Trials 1986; 7:177-88.

27 Göpel W, Kribs A, Ziegler A, et al. German Neonatal Network. Avoidance of mechanical ventilation by surfactant treatment of spontaneously breathing preterm infants (AMV): an open-label, randomised, controlled trial. Lancet 2011;378:1627-34.

28 Kanmaz HG, Erdeve O, Canpolat FE, et al. Surfactant administration via thin catheter during spontaneous breathing: randomized controlled trial. Pediatrics 2013;131:e502-9.

29 Mirnia K, Heidarzadeh M, Hosseini M, et al. Comparison outcome of surfactant administration via tracheal catheterization during spontaneous breathing with InSurE. Med J Islamic World Acad Sci 2013;21:4, 143-8.

30 Bao $Y$, Zhang $G$, Wu $M$, et al. A pilot study of less invasive surfactant administration in very preterm infants in a Chinese tertiary center. BMC Pediatr 2015;15:21.

31 Mohammadizadeh M, Ardestani AG, Sadeghnia AR. Early administration of surfactant via a thin intratracheal catheter in preterm infants with respiratory distress syndrome: Feasibility and outcome. J Res Pharm Pract 2015;4:31-6.

32 Kribs A, Roll C, Göpel W, et al. Nonintubated surfactant application vs conventional therapy in extremely preterm infants: a randomized clinical trial. JAMA Pediatr 2015;169:723-30.

33 Abdel-Latif ME, Osborn DA. Nebulised surfactant in preterm infants with or at risk of respiratory distress syndrome. Cochrane Database Syst Rev 2012;10:CD008310.

34 Minocchieri S, Knoch S, Schoel WM, et al. Nebulizing poractant alfa versus conventional instillation: Ultrastructural appearance and preservation of surface activity. Pediatr Pulmonol 2014;49:348-56.

35 Abdel-Latif ME, Osborn DA. Laryngeal mask airway surfactant administration for prevention of morbidity and mortality in preterm infants with or at risk of respiratory distress syndrome. Cochrane Database Syst Rev 2011;(7):CD008309.

36 Sinclair SE, Chi E, Lin HI, et al. Positive end-expiratory pressure alters the severity and spatial heterogeneity of ventilator-induced lung injury: an argument for cyclical airway collapse. J Crit Care 2009;24:206-11.

37 Dargaville PA. Innovation in surfactant therapy I: surfactant lavage and surfactant administration by fluid bolus using minimally invasive techniques. Neonatology 2012:101:326-36.

38 Bohlin K, Bouhafs RK, Jarstrand C, et al. Spontaneous breathing or mechanical ventilation alters lung compliance and tissue association of exogenous surfactant in preterm newborn rabbits. Pediatr Res 2005;57:624-30.

39 Gopel W, Kribs A, Hartel C, et al. Less invasive surfactant administration is associated with improved pulmonary outcomes in spontaneously breathing preterm infants. Acta Paediatr 2015;104:241-6.

40 Dekker J, Lopriore E, Rijken $\mathrm{M}$, et al. Sedation during Minimal Invasive Surfactant Therapy in Preterm Infants. Neonatology 2016;109:308-13.

41 Porath M, Korp L, Wendrich D, et al. Surfactant in spontaneous breathing with nCPAP: neurodevelopmental outcome at early school age of infants $\leq 27$ weeks. Acta Paediatr 2011;100:352-9. 


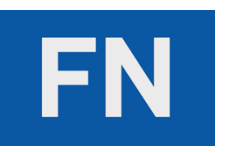

Less invasive surfactant administration versus intubation for surfactant delivery in preterm infants with respiratory distress syndrome: a systematic review and meta-analysis

Jose C Aldana-Aguirre, Merlin Pinto, Robin M Featherstone and Manoj Kumar

Arch Dis Child Fetal Neonatal Ed 2017 102: F17-F23 originally published online November 15, 2016

doi: 10.1136/archdischild-2015-310299

Updated information and services can be found at:

http://fn.bmj.com/content/102/1/F17

References

Email alerting service

\section{These include:}

This article cites 37 articles, 8 of which you can access for free at: http://fn.bmj.com/content/102/1/F17\#BIBL

Receive free email alerts when new articles cite this article. Sign up in the box at the top right corner of the online article.

Topic Articles on similar topics can be found in the following collections

Collections
Editor's choice (55)
Child health (1515)
Mechanical ventilation (88)
Bronchopulmonary dysplasia (95)
Clinical trials (epidemiology) (252)
Epidemiologic studies (929)

\section{Notes}

To request permissions go to:

http://group.bmj.com/group/rights-licensing/permissions

To order reprints go to:

http://journals.bmj.com/cgi/reprintform

To subscribe to BMJ go to:

http://group.bmj.com/subscribe/ 